\section{Passing the Baton to the Second Acquired Wisdom Editorial Team}

\section{Sigmund Tobias, J. D. Fletcher, and David C. Berliner}

The series, Acquired Wisdom. Lessons Learned by Distinguished Researchers $(A W)$ has attracted a good deal of notice. As we, the founding AW editors, pass the baton to a new editing team we have prepared these notes to summarize the history of the series, our decisions regarding its release, some of what we have learned from editing this series, and our hopes for its future.

\section{History}

The AW series was stimulated by a request to Tobias, after his retirement from the faculty of the City College of New York, to prepare an essay that might be useful to new City College faculty. It occurred to him that a series in which distinguished researchers described the lessons they had learned during their careers might be helpful to colleagues, especially graduate students and those newly entering the field. Dexter Fletcher and David Berliner agreed that such a series would be useful and signed on as co-editors. We believed that an AW series would provide an opportunity for prominent senior members in the education and training community to author chapters and thereby share their knowledge and experience.

Some readers may question our inclusion of training with education. After all, the two focus on different venues and audiences. Training primarily concerns instruction for post-secondary learners preparing for employment in industry and the military. It prepares learners for specific jobs and occupations and is intended and required to produce individuals who have attained the specific learning objectives needed to accomplish specific tasks, jobs, and occupations.

Education provides instruction for learners of all ages, but it generally concerns younger learners in primary and secondary education. It is more flexible than training and prepares learners to pursue different paths to a full and fruitful life. Like training, it is guided by learning objectives, but it allows learners more personal choice and variation in accord with their interests, goals, and capabilities.

Nonetheless both training and education employ similar, if not the same, methods and procedures, and both rely on similar bodies of knowledge and research about cognition, learning, memory, and instructional processes. Despite this common ground, contact and communication between training and educational researchers, designers, practitioners, and evaluators is limited. Our view is that training and education are simply at different ends of the same continuum, which might be labelled as instruction-the intentional acquisition and development of learning. We hoped AW would narrow the gap between them through the exchange of knowledge, findings, and personal experience.

A prior effort to bridge the distance between these communities (Tobias \& Fletcher, 2000) did not attract much 
attention. This time around, we expected that including distinguished representatives from both communities in the AW series would stimulate closer relationships between them. As we now leave the scene, we wish we had attracted more contributions from the many psychologists and researchers working on training issues. We hope that successive editors will continue to pursue this goal.

An advisory committee was assembled to help select a list of senior scholars in both education and training who had recently retired, or were approaching retirement, but who remained active and could contribute chapters. We hoped that their chapters would help explicate their tacit knowledge, which could be passed to others entering the field. Tacit knowledge is rarely fully articulated or provided systematically, but more often conveyed by example (e.g., Sternberg \& Hedlund, 2002). Our intention was that the AW series would more explicitly and systematically present some of that knowledge and pass it on.

Invitations to prospective authors asked them to prepare chapters any way they wished, but we requested that the manuscripts provide: 1) A bit of their personal history; 2) their major contributions; 3 ) the personal and situational factors (institutions, colleagues, advisors, students) stimulating their most significant work, and 4) recommendations and lessons learned during their career that could be implemented by colleagues, especially those who are newly entering, or planning to enter, the field. We felt that it was vital to include the first three components because chapters dealing only with item 4 might suffer the fate of cookbooks with perfectly good recipes but left to gather dust on shelves. Buoyed by the stories of prominent members of our field, we hoped new entrants might better understand the range of possibilities available to them in the field.

To orient future authors about the type of manuscript sought and help them include the tacit knowledge they had acquired during their careers we attached the first draft of a sample chapter (Tobias, 2016) to the initial set of invitations. As more chapters were released, prospective authors were encouraged to examine them to see the type of manuscript expected.

A prestigious publisher of educational psychology and educational research materials offered us a contract for a three-volume series. Discussion with the publisher's representatives indicated that the length of manuscripts would have to be limited to keep prices down. Despite that, the minimal cost was estimated to be $\$ 175$ per volume. Clearly, that would have made the volumes too expensive for many colleagues, especially those newly entering the field and for whom the AW series was most likely to be helpful. Therefore, we unanimously agreed to have the series released over the Internet by Arizona State University as part of their extensive list of scholarly materials already on-line and freely accessible to everyone. As of August 23, $2018,23,478$ chapter abstracts were viewed and 17,901 chapters were downloaded, suggesting, perhaps, an intention to peruse them more thoroughly or to share them with others.

\section{Disappointments}

Our major disappointment is that a few of those who were invited to write chapters, and in some cases had started work on them, passed away before they could complete the task. They included Bruce Biddle, Barak Rosenshine, Gavriel Salomon, and Patrick Suppes. Several other distinguished researchers declined our invitation due to health situations or for reasons of declining capability. All these researchers made important contributions during the careers and had a great deal of wisdom to share. We regret that their wisdom and recommendations to colleagues will not be shared through AW. Some distinguished researchers declined our invitations because they were too committed to other work to squeeze AW into their schedule. Given their contributions and seniority, we can only be pleased to hear of their continued productivity. We hope AW 
will eventually capture their thoughts and reflections as its work continues.

Our work on AW inevitably overlooked some distinguished researchers who might well have been included. In fields as large as psychology and research on instruction, such oversights may be unavoidable - and we hope forgiven. We provided a list of invitees whom we missed and recommend for inclusion during our tenure to the incoming AW editorial team.
A list of authors whose AW chapters were edited by our team is shown in Table 1. A few chapters, not included in the table below, are still in process and we and the new editors have agreed that we will complete editing those and release them once they are completed. AW chapters may be read or downloaded at http://edrev.asu.edu/index.php/ER by clicking on the desired chapter.

Table 1

Contributing AW Authors and Titles, Volume 1

\begin{tabular}{|l|l|}
\hline John Sweller & The Story of A Research Program \\
\hline James Paul Gee & $\begin{array}{l}\text { Ramblings of an Old Academic: Unconfident Advice for End-times } \\
\text { Academics }\end{array}$ \\
\hline Sigmund Tobias & $\underline{\text { No Panacea Garden }}$ \\
\hline David Berliner & $\underline{\text { An Unanticipated Successful Career and Some Lessons Learned }}$ \\
\hline Robert Sternberg & $\begin{array}{l}\text { Wisdom Applied: The Secret Sauce That Has Allowed Me Already To } \\
\text { Have Achieved Immortality }\end{array}$ \\
\hline Alan Lesgold & $\underline{\text { It Takes a Village of Mentors }}$ \\
\hline Dee H. Andrews & $\begin{array}{l}\text { Training Research and Development: Retrospective of a Career in the } \\
\text { Defense Department }\end{array}$ \\
\hline M. David Merrill & $\underline{\text { A 50+ Year Search for Effective, Efficient and Engaging Instruction }}$ \\
\hline Henry L. Taylor & $\underline{\text { It Takes Two }}$ \\
\hline Sonia Nieto & On Reconciling Divergent Ideas: A Life-long Quest \\
\hline $\begin{array}{l}\text { Frederick } \\
\text { Erickson }\end{array}$ & $\begin{array}{l}\text { Some Lessons Learned About Teaching, Research, and Academic } \\
\text { Disputation }\end{array}$ \\
\hline $\begin{array}{l}\text { Catherine E. } \\
\text { Snow }\end{array}$ & $\underline{\text { Doubling Down on Serendipity }}$ \\
\hline $\begin{array}{l}\text { Michael S. Knapp } \\
\text { Bernard Weiner }\end{array}$ & $\underline{\text { Building Bridges between People, Ideas, and Possibilities: An Education }}$ \\
\hline $\begin{array}{l}\text { Professor Looks Back } \\
\text { Sigmund Tobias, }\end{array}$ & $\begin{array}{l}\text { Passing the Baton to the Second Acquired Wisdom Editorial Team } \\
\text { David E. Berliner }\end{array}$ \\
\hline
\end{tabular}

\section{What We Learned}

The diversity in the professional biographies of our authors was striking, but we noticed some trends and commonalities. For instance and surprisingly, many authors were poor students earlier in their academic lives, indicating that present performance may not be an accurate indicator of capacity, or future performance. Bright, curious individuals may be continually disappointed and bored by the deliberate pace of classroom instruction, eventually leading them to view formal, school education as unchallenging, uninteresting, and irrelevant to their interests. As a result, they may acquire lax, or absent, study habits relevant to formal learning settings. When they encounter higher education or other more challenging venues, they may find themselves in more challenging instructional environments in company with capable 
individuals who earlier acquired appropriate study habits and learning abilities. At some point their attitudes toward formal education and lax study habits may catch up with them and hinder their promise and progress_an issue echoing Carroll's (1974, 1977) interest in the importance of learning ability as requisite for academic success.

A source of this problem may be the inability of classroom instruction to adjust the pace of instruction to individual students. As long ago as 1906, Thorndike noted that: "the principal consequence of individual differences is that every general law of teaching has to be applied with consideration of the particular person [because] responses to any stimulus will vary with individual capacities, interests, and previous experience” (p. 83). Such adjustments allow instruction to, among other matters, accommodate the time different students need to achieve given instructional objectives.

Today, as in Thorndike's time, time to learn varies dramatically. For instance, Glaser found a ratio of 5:1 for the number of instructional units in an arithmetic curriculum mastered over a period of three years (Glaser, 1968). Gettinger and White (1980) found that the times needed for fifth grade students to master a unit of social studies varied by $3: 1$ and 5:1. Suppes, Fletcher, and Zanotti (1975) found that the ratio of time needed by hearing impaired and Native American students to reach mathematics objectives averaged about 4:1.

Doubtless these ratios are due to a number of factors, but as Tobias (1989) suggested, prior knowledge appears to be a major factor, one that quickly overtakes native ability in accounting for the speed of learning. Interestingly, Corbett (private communication, 1998) reported a ratio of $7: 1$ for university undergraduates, with presumably greater amounts and varieties of prior learning, to learn features of the LISP programming language. His results and others from post-secondary and military training suggest that the need for individualization increases with the age and experience of the learner, further supporting Tobias' suggestion.

In sum, rather than encouraging our most promising students, our elementary and secondary classrooms may do just the opposite for them by failing to inspire and encourage trust in formal education as a way to support their curiosity and interests. To a degree this practice is necessary if all learners in a typical classroom are to meet established thresholds of learning. Teachers must attend to those who are struggling to learn, but, as is often noted, it wastes the time, talent, and motivation, of promising students, perhaps preventing many of them, including some prominent contributors to AW, to attend seriously to formal education.

Reducing class size has been suggested as a way to ameliorate the problem. Data on the effects of reducing class size has long been favorable, but the quality of the research has also been subject to criticism (Finn, Pannozzo, \& Achilles, 2003). To an extent, the use of computers has long been sought to provide individualized instruction (Atkinson, 1968; Suppes, 1964). There is evidence that such digital tutoring is both possible and successful (Kulik \& Fletcher, 2016; Van Lehn, 2014) sometimes substantially so (Fletcher \& Morrison, 2014).

We did not find socio-economic status of our authors' background and families to be a factor in their success. Their socio-economic statuses varied greatly, ranging from poverty to some who appeared to have been financially comfortable. Further, our authors were just as likely to have attended average academic institutions as major research universities, supporting the impression that the top ten percent of individuals at all higher education institutions are similar in ability and promise.

We hope that the AW series will assist and encourage the mentoring process. Many AW contributors noted that a senior colleague, instructor, or mentor was vital in encouraging and stimulating their 
development. Senior researchers and faculty in all institutions should note the importance of identifying, mentoring, and encouraging, promising junior people in their work and involving them in their work and research. We hope that the AW series can assist in the mentoring process. Our authors were, and in many cases continue to be, distinguished contributors to the field and mentors might consider assigning some AW chapters to those they are mentoring, especially if the authors' research is related to their own work. Furthermore, we were pleased to hear that some colleagues are using AW chapters as virtual mentors and assigning them to graduate students. Because our series is freely available to everyone, we encourage its use as a mentoring resource, in addition to assigning appropriate chapters to classes.

Perhaps the greatest similarity in the professional biographies of our authors is that they worked hard in their chosen profession, producing numerous research articles, technical reports, reviews, chapters, and books. In most cases, they also grew proficient in writing grant applications to secure the support needed to pursue their work. Clearly, their lives were substantively different from the stereotype of the relaxed, professorial lives often attributed to academics. All our authors were devoted to their fields and worked hard at it. Their work ethic is reminiscent of Roe's (1953) original finding that eminent scientists could be distinguished from their less productive colleagues more by their hard work than by personal characteristics obtained from formal tests of ability or personality.

\section{Suggestions for the Future}

Examining our list of authors leads to some suggestions for the future. Although a number of our authors were born in other countries, they had, with one exception, spent their working lives in the United States. Clearly, more effort than we had time to provide should be given to inviting chapters from distinguished researchers in other countries. Similarly, and despite our efforts, very few females, minority scholars, or members of the training community have appeared as AW authors. More effort in that direction is needed. Also, as we learned, it is important to identify and approach distinguished, aging scholars sooner rather than later to better ensure their ability to complete the task.

Finally, the work of our authors was generally in the fields of educational psychology and educational research. Future editors may wish to consider including authors from related fields such as measurement and evaluation, personality, social psychology, sociology, artificial intelligence, and even economics (e.g., return on investment) as they relate to education and training.

While we have been pleased by the data indicating that the AW series is widely read, future editors might consider getting feedback from the field about the series. That could be accomplished informally by asking for readers' evaluations of AW, or by conducting a formal evaluation. External feedback is always useful and often provides suggestions for important future directions. Editors can substantially profit from other views and, especially, evolving approaches in our field of education and training.

We look forward to reading chapters edited by subsequent teams of AW editors and hope that the wide readership attained by the initial chapters will continue and even increase. We wish them well and great success in this very interesting endeavour.

\section{References}

Atkinson, R. C. (1968). Computer based instruction in initial learning. In Proceedings of the 1967 Invitational Conference on Testing Problems. Princeton, NJ: Educational Testing Service. 
Carroll, J. B. (1974). Fitting a model of school learning to aptitude and achievement data over grade levels. In D. R. Green (Ed.), The aptitude-achievement distinction. Monterey, CA: McGraw-Hill.

Carroll, J. B. (1977). A revisionist model of school learning. Review of Education, 3, 155-167.

Finn, J. D., Pannozzo, G. M., \& Achilles, C. M. (2003). The "Why's" of class size: Student behavior in small classes. Review of Educational Research, 73, 321-368.

Fletcher, J. D., \& Morrison, J. E. (2014). Accelerating development of expertise: A digital tutor for Navy technical training (D-5358). Alexandria, VA: Institute for Defense Analyses.

Gettinger, M., \& White, M. A. (1980). Evaluating curriculum fit with class ability. Journal of Educational Psychology, 72, 338-344.

Glaser, R. (1968). Adapting the elementary school curriculum to individual performance. In Proceedings of the 1967 Invitational Conference on Testing Problems. Princeton, NJ: Educational Testing Service.

Kulik, J. A, \& Fletcher, J. D. (2016). Effectiveness of intelligent tutoring systems: a meta-analytic review. Review of Educational Research, 86, 42-78.

Roe, A. (1953). A psychological study of eminent psychologists and anthropologists, and a comparison with biological and physical scientists. Psychological Monographs, 67(2), 1-55. https://doi.org/10.1037/h0093638

Sternberg, R., \& Hedlund, J. (2002). Practical intelligence, g, and work psychology. Human Performance, 15, 143-60.

Suppes, P. (1964) Modern learning theory and the elementary-school curriculum. American Educational Research Journal, 1, 79-93.

Suppes, P., Fletcher, J. D., \& Zanotti, M. (1975). Performance models of American Indian students on computer-assisted instruction in elementary mathematics. Instructional Science, 4, 303-313.

Thorndike, E. L. (1906). Principles of teaching. New York, NY: A. G. Seiler \& Company.

Tobias, S. (1989). Another look at research on the adaptation of instruction to student characteristics. Educational Psychologist, 24, 213-227.

Tobias, S. (2016, April 13). No Panacea Garden. In S. Tobias, J. D. Fletcher, \& D. Berliner (Series Eds.), Acquired Wisdom Series, Vol 1. Education Review, 23. http://dx.doi.org/10.14507/er.v23.2060

Tobias, S., \& Fletcher, J. D. (Eds.) (2000). Training and retraining: A bandbook for business, industry, government, and the military. New York, NY: Macmillan.

Vanlehn, K. (2011). The relative effectiveness of human tutoring, intelligent tutoring systems, and other tutoring systems. Educational Psychologist, 46(4), 197-221. 


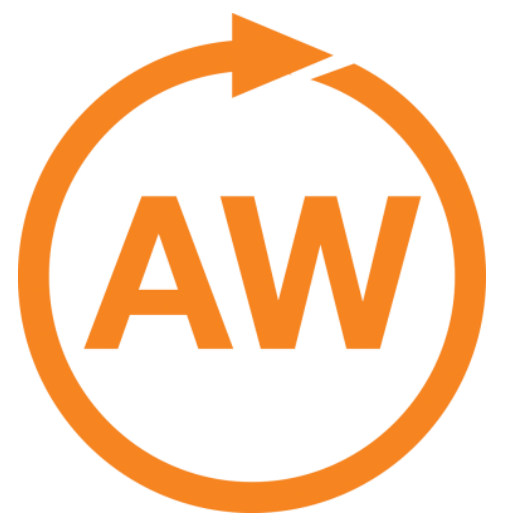

\section{About Acquired Wisdom}

The history and development of the AW series has been described in the preceding essay. Colleagues, junior faculty and graduate students in Educational Psychology, Educational Research, and related disciplines, could learn much from the experiences of senior researchers. Doctoral students are exposed to courses or seminars about history of the discipline as well as the field's overarching purposes and its important contributors.

A second audience for this project include the practitioners and researchers in disciplines represented by the chapter authors. This audience could learn from the experiences of eminent researchers-how their experiences shaped their work, and what they see as their major contributions_-and readers might relate their own work to that of the scholars. Invitations to potential authors were accompanied by Tobias' chapter in this series for illustrative purposes. Authors were advised that they were free to organize their chapters as they saw fit, provided that their manuscripts contained these elements: 1) their perceived major contributions to the discipline, 2) major lessons learned during their careers, 3) their opinions about the personal and 4) situational factors (institutions and other affiliations, colleagues, advisors, and advisees) that stimulated their significant work.

We hope that the contributions of distinguished researchers receive the wide readership they deserve and serves as a resource to the future practitioners and researchers in these fields. 


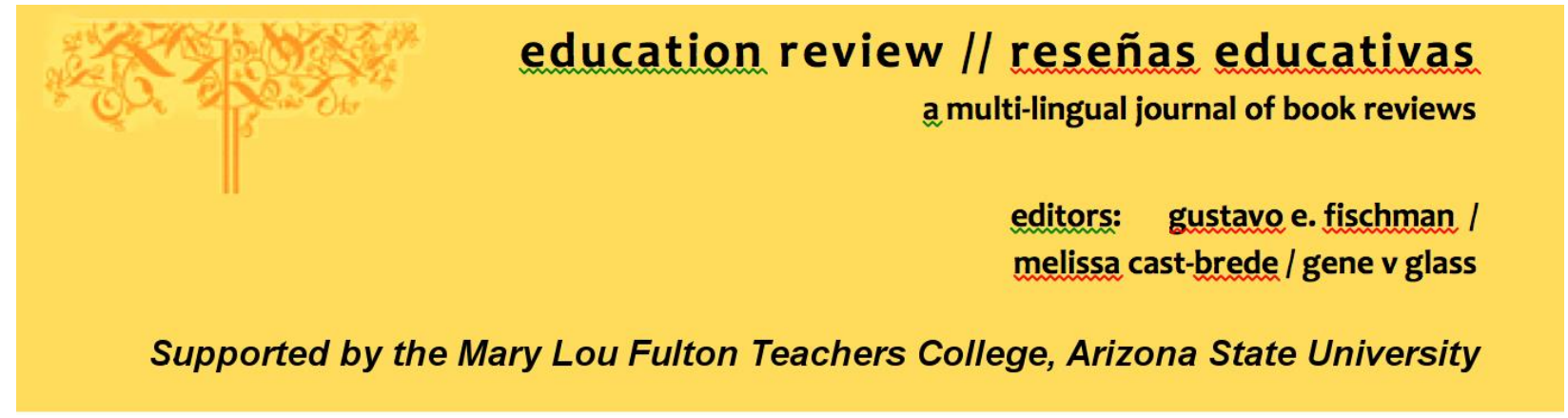

\section{Acquired Wisdom Editors}

Sigmund Tobias

University at Albany

State University of New York

\section{J. D. Fletcher}

Institute for Defense Analyses

Alexandria VA
David C. Berliner

Arizona State University

Tempe AZ

\section{Advisory Board Members}

Gustavo Fischman, Arizona State University

Arthur C. Graesser III, Memphis State University

Teresa L. McCarty, University of California Los Angeles

Kevin Welner, Colorado State University

\footnotetext{
Education Review/Reseñas Educativas/Resenhas Educativas is supported by the edXchange initiative's Scholarly Communications Group at the Mary Lou Fulton Teachers College, Arizona State University. Copyright is retained by the first or sole author, who grants right of first publication to the Education Review. Readers are free to copy, display, and distribute this article, as long as the work is attributed to the author(s) and Education Review, it is distributed for non-commercial purposes only, and no alteration or transformation is made in the work. More details of this Creative Commons license are available at http://creativecommons.org/licenses/by-nc-sa/3.0/. All other uses must be approved by the author(s) or Education Review. Education Review is published by the Scholarly Communications Group of the Mary Lou Fulton Teachers College, Arizona State University.

Connect with Education Review on Facebook (https://www.facebook.com/pages/EducationReview/178358222192644) and on Twitter @EducReview
} 